\title{
DEVELOPMENT ON SLEEP MONITORING SYSTEM \\ CONFIGURATION TOWARD AN OPTIMAL AMBIENT CONDITION SETTING OF THE SLEEP QUALITY
}

\section{W.H.M. Saad ${ }^{1}{ }^{*}$, A.S.M. Shokri², S.A. Radzi ${ }^{1}$, S.J.A. Razak ${ }^{3}$ and M.N.S. Zainudin $^{1}$}

${ }^{1}$ Faculty of Electronics and Computer Engineering.

${ }^{2}$ Faculty of Electrical and Electronics Engineering Technology.

Universiti Teknikal Malaysia Melaka, Durian Tunggal, 76100, Melaka, Malaysia.

${ }^{3}$ SolokFertigasi by MSJ Perwira Enterprise.

75460 Duyong, Melaka, Malaysia.

"Corresponding Author's Email: ${ }^{1}$ wira_yugi@utem.edu.my

Article History: Received July 1, 2021; Revised July 12, 2021;

Accepted July 16, 2021

\begin{abstract}
Sleep is a form of rest and getting enough sleep at the right times with suitable surrounding conditions is very important to maintain good health throughout life. The study aims to develop the end-user prototyping for a sleep monitoring system that measures the room ambient and body condition by using a wireless device utilizing Bluetooth Low Energy (BLE) embedded system. For the user interface, the Window application is used to display the collected data from separate ambient parameters and body condition embedded systems using Bluno Uno and Bluno Nano respectively. This sleep monitoring system is also equipped with a video and audio recording from the web camera and microphone of the built-in PC-based unit. Capturing data from body monitoring and ambient monitoring separate units are then transferred to the Window based application by using the BLE connection and lastly, the captured data are log into the MySQL database with the date and time stamp. The ambient condition system captured the room temperature and humidity, light intensity and rate of $\mathrm{CO}_{2}$ concentration. The body condition system, it is measuring body temperature, heart rate and body movement. Based on the device testing on sleep monitoring, each of the parameters measured is optimized to choose the best possible occurrence of ambience setting selection for optimal sleep quality.
\end{abstract}

KEYWORDS: Sleep Monitoring Systems; Ambient Monitoring Systems; Body 
Monitoring Systems; Bluetooth Low Energy (BLE).

\subsection{INTRODUCTION}

Sleep satisfaction is one of the keys to achieving the ultimate goal of a healthy body. While in sleep, our body is resting and conserving energy while restoration our tissues and cognitive function, emotion regulation, and immune health [1]. The pathological changes to our hormonal balance in the body between glycogen and adenosine after waking up from enough sleep making us feel refresh. Most of the restoration of energy occur while in non-REM sleep or also known as deep sleep [2]. On the other hand, the rapid eye movement (REM) sleep stage is when our eye is moving in a range of directions without sending any visual information to the brain [2]-[4]. Dreams often occur while in REM sleep and that is why REM sleep is also known as dream sleep. While sleeping with eyes closed, REM can be measured by using Electromyograph (EMG) device with electrodes located surrounding the eyes. Some other physiological body condition also varies while we are sleeping and this includes brain activity, body temperature, heart rate, oxygen level, carbon dioxide level and breathing rate [2]. This parameter often uses by the monitoring system that falls either under medical devices or consumer products to represent sleep quality.

The sleep monitoring system function as a device to quantify the parameter of sleep quality representation characteristic based on its purpose [5]-[8]. For example, a medical-grade device that is used to measure obstructive sleep apnea (OSA) often utilises the pneumotachograph sensor, nasal pressure transducer, and oronasal thermal sensor with pulse oximetry to diagnose the abnormality in airflow, snoring breathing rate and oxygen level to diagnose the patient. On the other hand, the sleep monitoring device for personal daily use often measure heart rate and movement and estimated the quality of the sleep based on the continuous pattern and behaviour of the measured data.

In this study, the aim is to propose the development of a sleep monitoring device for personal use that incorporated ambient and body condition measurement to get more insight on making a deductive interpretation toward an optimum sleep quality. Previously, such a conceptual system has been proposed in [7], [9] and with an additional measurement parameter that is done in this study, it requires a simple modification on device development configuration 
and validation measurement that is emphasized by this manuscript. The functionality presented by the proposed device allowing the user to escalate the best surrounding condition that highly contribute to their personalise sleep preferences requirement to achieve a good sleep quality by customizing the ambient itself.

This paper consists of four major sections including this section. Section 2.0 consists of the methodology development of the sleep monitoring system for the body and ambient. Then, Section 3.0 encompasses the experiment result from on-device testing and discussion. Lastly, Section Error! Reference source not found. concludes the work and future direction.

\subsection{METHODOLOGY}

The proposed sleep monitoring system consists of two parts which are the ambient condition system and body condition system. An ambient condition system as shown in Figure 1 equipt with a sensor that can measure the surrounding environment such as temperature, humidity, light intensity, noise and quality of air.

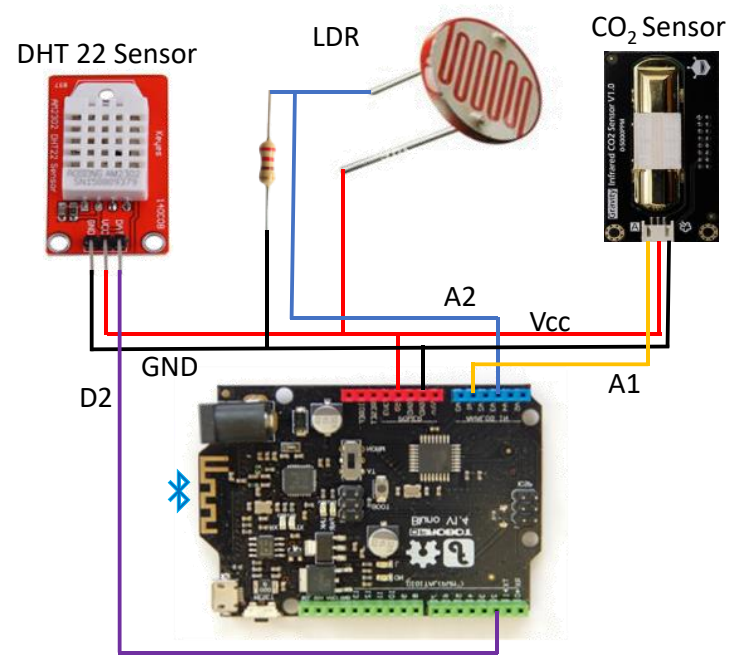

Figure 1: Circuit configuration for ambient monitoring system

For the body condition system as shown in Figure 2, the sensor will monitor the body condition of the user while sleeping such as heart rate, body temperature and body movement. Both systems are equipped with Bluetooth Low Energy (BLE) connectivity and readings generated from both systems were collected by using PC for data 
logging and visualisation. Both systems consist of a microcontroller that is programmed by using Arduino IDE and the Window Application that will display the readings was designed by using Microsoft Visual Studio 2015. The architecture of the sleep monitoring system can be seen in Figure 3.

For the ambient monitoring system, BLUNO UNO is working with a digital temperature and humidity sensor (DHT22), a light-dependent resistor (LDR) and a $\mathrm{CO}_{2}$ gas sensor to capture the reading of light intensity, humidity, room temperature and quality of air in the surrounding ambient where the user sleep. Then, in the body condition system, BLUNO NANO is working with a pulse sensor, accelerometer and thermistor to capture the reading of heart rate, body temperature and body movement while the user is sleeping. The functional prototype of the ambient condition system and body condition system has been designed and prepared as shown in Figure 4. From the figure, the prototype of the body condition system has been designed in the form of a wearable belt that will be wear as a chest strap by the user during sleep and on the other hand, the prototype of the ambient condition system will be placed on the bedside table next to where the user is sleeping as shown in Figure 5.

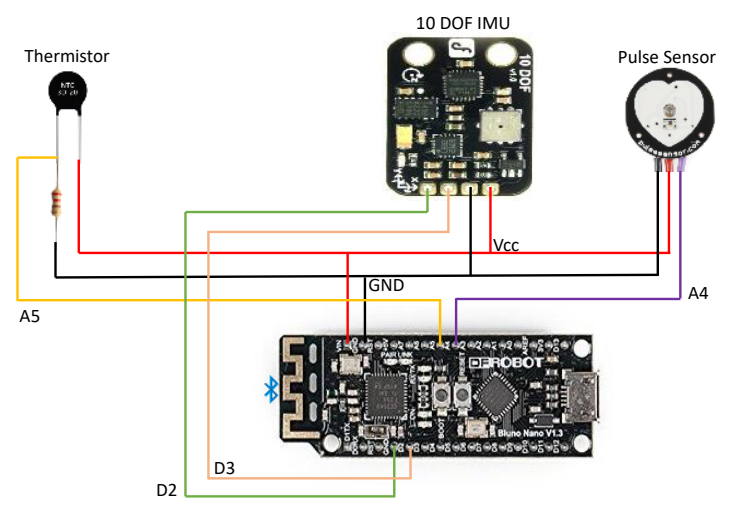

Figure 2: Circuit configuration for body condition monitoring system 

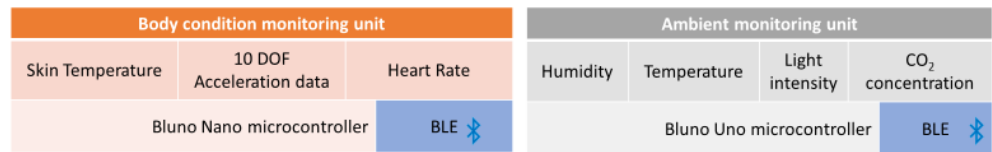

\begin{tabular}{|l|l|l|l|}
\hline \multicolumn{3}{c}{ Sleep monitoring CPU unit } & \\
Camera & Microphone & Data logging & GUI \\
& & CPU & BLE $\&$
\end{tabular}

Figure 3: Sleep monitoring system software architecture

The data captured by both systems were transferred to window apps via Bluetooth connection. Window apps were designed using Microsoft Visual Studio 2015 will display the readings that have been received and logged the data into the MySQL database. Several tables were created in the database to update the time and value of each parameter. In addition, users can enable the video and audio recording functionality from a camera and microphone of the PC. Figure 6 shows the GUI of the sensor status triggered from both ambient and body condition monitoring systems on the designed Window Apps.

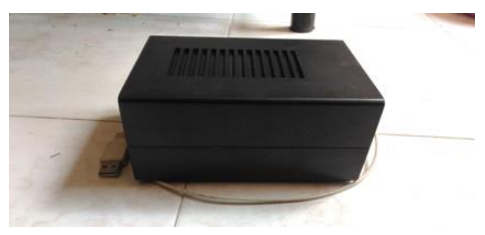

(a)

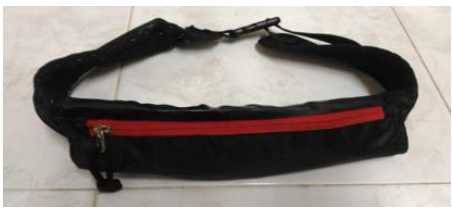

(b)

Figure 4: Prototype of (a) ambient and (b) body condition monitoring system 


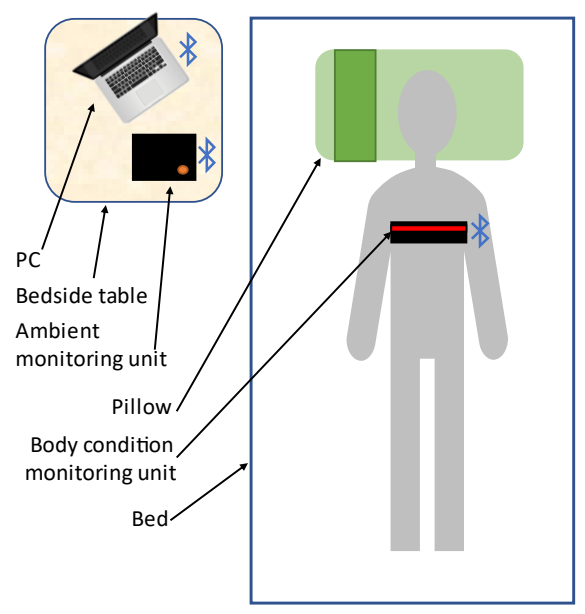

Figure 5: Scenario of the sleep monitoring system while the subject is on the bed

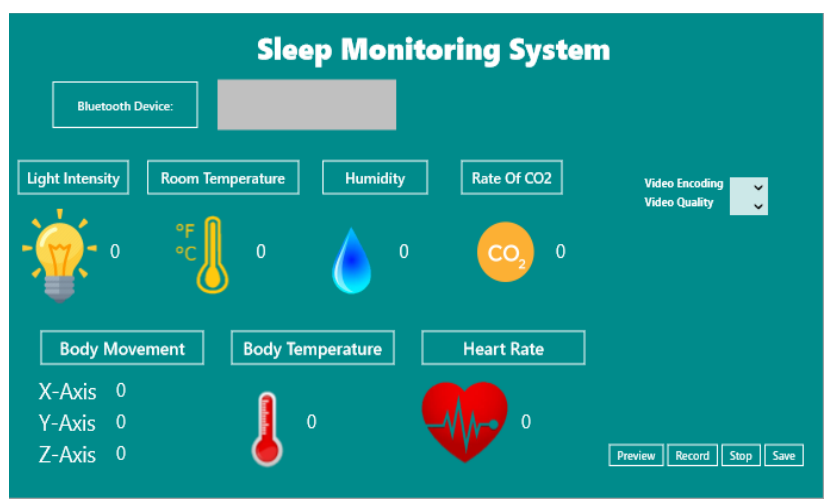

Figure 6: Graphical user interface (GUI) of Sleep monitoring system application

In general, the flowchart of the overall development methodology can be seen in Error! Reference source not found.. The development starts with circuit design and fabrication for each monitoring system then followed by GUI development on Window Apps then continued by communicating each microcontroller used with the application on Window apps through serial communication port through BLE. 


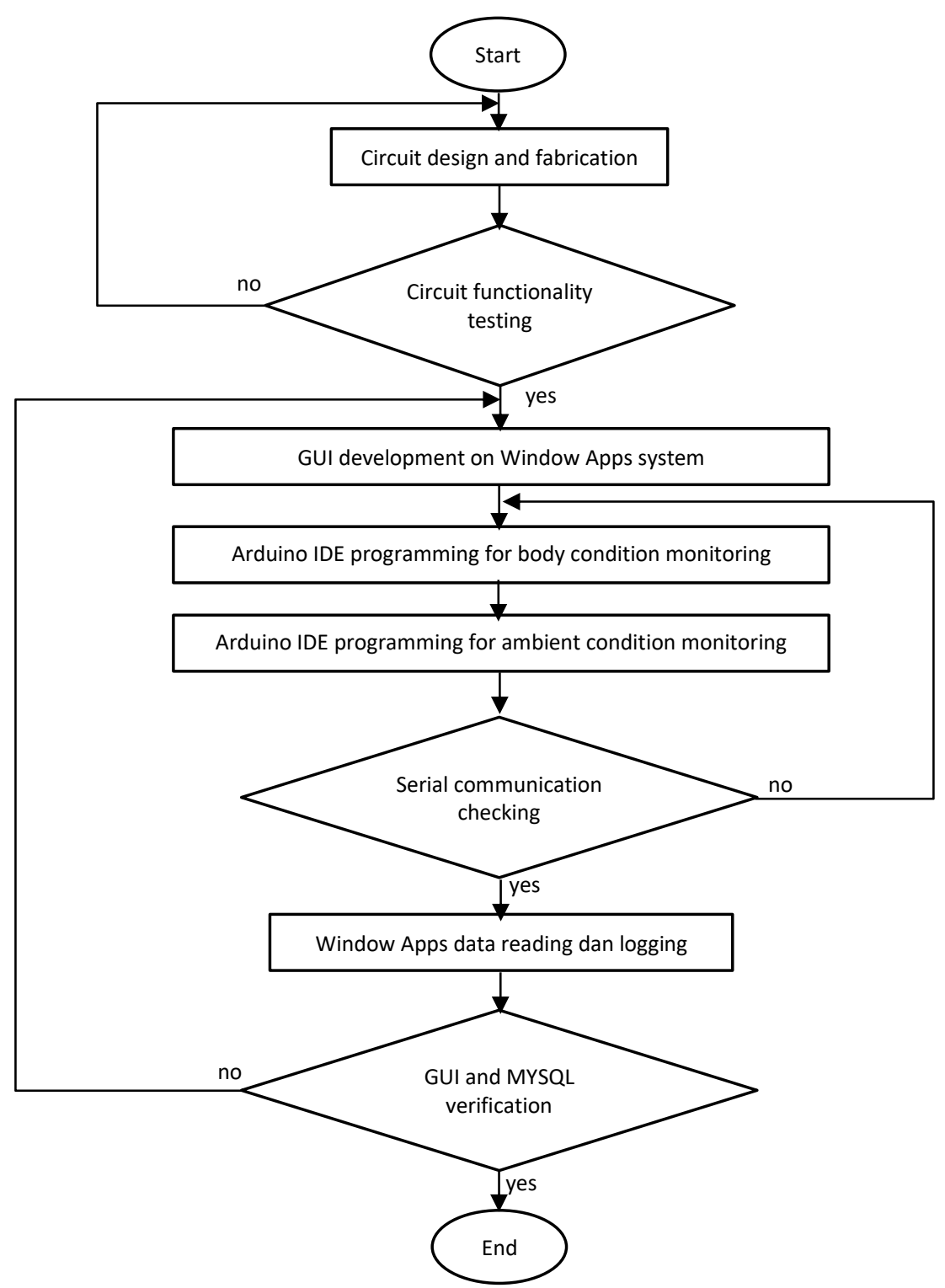

Figure 7: Overall methodology of sleep monitoring system development

To use the sleep monitoring system, both the ambient condition system and body condition system need to be power on first. The body condition system was designed to be powered up by using a rechargeable lithiumpolymer battery for portability as it is directly fitted on the user body while 
the ambient condition system can be directly power up through a USB connection plug giving a convenient option to the user either to plug it directly on the PC or plug it into the USB power source. A lithium polymer battery also called LiPo battery is chosen to supply sufficient power to the body condition system as it is rechargeable, light and smaller and it can power up the system all night long without running out of battery.

The second step is to pair both systems that have been powered on with PC through Bluetooth $>$ Manage Bluetooth Device on system setting using with preset pairing password. Once it is paired, it will appear as "Bluno.Core.BlunoDevice" in the Bluetooth device list view in the Apps. GUI indicating both devices have been connected to the PC. Then, the Windows application will display the reading captured from the microcontroller. Windows application will ask the user permission to access the camera and audio. When it already gets permission, the video and audio recorder can be used by clicking on the "Record" button to logging all the parameters.

\subsection{RESULT AND DISCUSSION}

When getting ready, all the equipment is turned on and paired to the PC accordingly. Before going to sleep, the subject had to wear the belt stripe of the body condition monitoring system at the chest and hit the record button on the GUI of Window Apps.

The experiment was carried out on a few different surrounding conditions to observe the effect of the individual perception on ambient conditions toward sleep quality. The experiment is done based on the normal sleep hour of the subject and the quality of sleep is measured based on the estimated duration of sleep transition. The example of the recorded data for both monitoring systems in the MySQL database is extracted and plot as can be seen in Figure 8 and Figure 9. From the plot of Figure 8, the sleep cycle from transition to light sleep, dream sleep and deep sleep is estimated based on the work done in [7], [9] where body conditions such as body temperature, heart rate and body movement are determined the sleep cycle stages.

Four parameters of ambient were investigated which are temperature, light intensity, humidity and $\mathrm{CO}_{2}$ concentration on the air as each of these parameters were reported to give some of the effects toward sleep quality [10]-[15]. Even though the parameter of the ambient is measured accurately by the sensor but in this study, the perception of the subject is what mostly matters in this experimental 
observation and at the same time, it is easier to control and maintain the value [16], [17]. The details on the ambient parameter perception set-up are listed in Table 1. Since $\mathrm{CO}_{2}$ concentration in the air can be affected by improper air ventilation in the bedroom throughout sleep time [11], the experiment is focused on the comparison between good air ventilation and improper air ventilation.

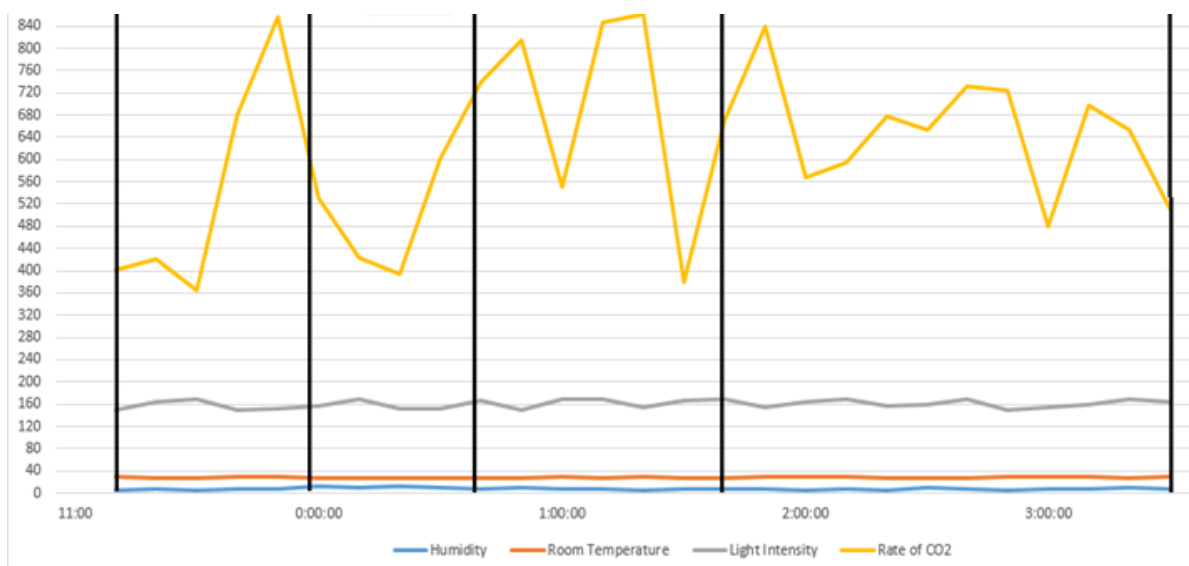

Figure 8: Changes in ambient condition measured

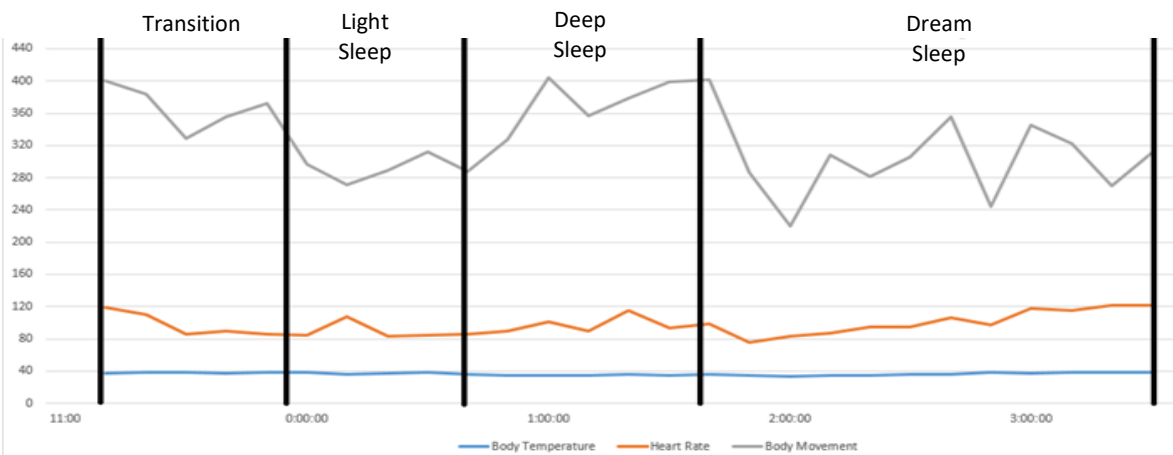

Figure 9: Changes in body condition measured

After that, the ambient condition system is placed on the table beside the bed where the sample is sleeping. The experiment is ready to start as all the connections have been done. In addition, the experiments are carried out starting when the sample sleep until the sample wakes up to observe any changes in the body condition to analyze the quality of sleep of the subject in their usual sleeping bedroom.

The main objective of running this experiment is to investigate preliminary in terms of each of the ambient parameters that can give effect to the duration of deep sleep and REM sleep. The measurement 
of each set was repeated for three-night nonconsecutively and the average measuring time was recorded and can be seen in Table 2. Each of the parameters is set up by turning on the devices uses with similar parameters each time it has been used to resulting in a similar control environment every time the experiment took place. The city location where the experiment took place is in Melaka, Malaysia $\left(2.1896^{\circ} \mathrm{N}\right.$, $\left.102.2501^{\circ} \mathrm{E}\right)$ where the climate here is hot and humid throughout the year.

Table 1: Four settings of ambient parameter set up

\begin{tabular}{|c|c|c|c|}
\hline $\begin{array}{c}\text { Ambient } \\
\text { parameters }\end{array}$ & Perception & $\begin{array}{c}\text { A targeted } \\
\text { condition set up }\end{array}$ & Other control parameters \\
\hline \multirow{2}{*}{$\begin{array}{l}\text { Setting 1: } \\
\text { Humidity }\end{array}$} & (a) Humid & $\begin{array}{c}\text { The humidifier was } \\
\text { turn on }\end{array}$ & \multirow{2}{*}{$\begin{array}{l}\text { - The airconditioning was turn on } \\
\text { - The light was turn off } \\
\text { - The ventilation fan was turned on }\end{array}$} \\
\hline & (b) Normal & $\begin{array}{l}\text { The humidifier was } \\
\text { turn off }\end{array}$ & \\
\hline \multirow{2}{*}{$\begin{array}{l}\text { Setting 2: } \\
\text { Room } \\
\text { Temperature }\end{array}$} & (a) Cool & $\begin{array}{l}\text { The airconditioning } \\
\text { was turn on }\end{array}$ & \multirow{2}{*}{$\begin{array}{l}\text { - The light was turn off } \\
\text { - The ventilation fan was turned on } \\
\text { - The humidifier was turn on }\end{array}$} \\
\hline & (b) Normal & $\begin{array}{c}\text { The airconditioning } \\
\text { was turn off }\end{array}$ & \\
\hline \multirow{2}{*}{$\begin{array}{l}\text { Setting 3: } \\
\text { Light intensity }\end{array}$} & (a) Bright & The light was turn on & \multirow{2}{*}{$\begin{array}{l}\text { - The airconditioning was turn on } \\
\text { - The ventilation fan was turned on } \\
\text { - The humidifier was turn on }\end{array}$} \\
\hline & (b) Dark & The light was turn off & \\
\hline \multirow{2}{*}{$\begin{array}{c}\text { Setting 4: } \\
\mathrm{CO}_{2} \text { concentration/ } \\
\text { Air Ventilation }\end{array}$} & $\begin{array}{ll}\text { (a) Good } & \text { ventilation } \\
& \text { ven }\end{array}$ & $\begin{array}{c}\text { The ventilation fan } \\
\text { was turned on }\end{array}$ & \multirow{2}{*}{$\begin{array}{l}\text { - The airconditioning was turn on } \\
\text { - The light was turn off } \\
\text { - The humidifier was turn on }\end{array}$} \\
\hline & $\begin{array}{ll}\text { (b) } & \begin{array}{l}\text { Poor } \\
\text { ventilation }\end{array} \\
\end{array}$ & $\begin{array}{c}\text { The ventilation fan } \\
\text { was turned off }\end{array}$ & \\
\hline
\end{tabular}

Table 2: Average time taken of each sleep cycle for different parameters conditions of the ambient setting.

\begin{tabular}{|c|c|c|c|c|c|c|}
\hline \multirow[b]{2}{*}{$\begin{array}{l}\text { Ambient } \\
\text { Parameter } \\
\text { Setting }\end{array}$} & \multicolumn{6}{|c|}{ Average Taken Time in Hours and Minutes (HH:MM) } \\
\hline & Transition & $\begin{array}{l}\text { Light } \\
\text { Sleep }\end{array}$ & $\begin{array}{l}\text { Deep } \\
\text { Sleep }\end{array}$ & $\begin{array}{l}\text { REM } \\
\text { Sleep }\end{array}$ & Total Sleep & $\begin{array}{c}\text { Deep } \\
\text { Sleep+REM } \\
\text { Sleep } \\
\end{array}$ \\
\hline Setting 1(a) & 00:31 & 00:57 & 01:09 & 02:48 & 05:27 $\pm 00: 12$ & 03:58 \\
\hline Setting 1(b) & $00: 23$ & $00: 27$ & 01:29 & $02: 48$ & 05:08 $\pm 00: 06$ & 04:18 \\
\hline Setting 2(a) & 00:26 & 00:48 & 01:08 & 03:08 & 05:31 $\pm 00: 18$ & 04:16 \\
\hline Setting 2(b) & 00:25 & 01:22 & $00: 33$ & 03:20 & 05:41 $\pm 00: 15$ & 03:53 \\
\hline Setting 3(a) & 00:24 & 01:25 & $00: 31$ & 03:22 & $05: 43 \pm 00: 10$ & 03:54 \\
\hline Setting 3(b) & $00: 24$ & $00: 47$ & 01:07 & 03:13 & $05: 33 \pm 00: 23$ & $04: 21$ \\
\hline Setting 4(a) & $00: 22$ & $01: 15$ & $00: 40$ & 03:16 & $05: 35 \pm 00: 16$ & 03:56 \\
\hline Setting 4(b) & $00: 22$ & $00: 55$ & 01:07 & 03:03 & 05:29 $\pm 00: 09$ & $04: 11$ \\
\hline
\end{tabular}

Based on the result shown in Table 2, generally, in most of the cases, the subject took about three hours in the dream sleep mode and 30 minutes to 1 hour in deep sleep mode. Comparatively by observing both deep sleep and REM sleep duration, subjects sleep better without 
the humidifier, with air conditioning turn on, light off and good air ventilation. Although, this is not conclusive enough to suggest the best ambient parameter condition for all cases since sleep preferences vary from one person to another and their preferences on the ambient setting night also are influenced by many reasons that are open for future investigation.

\subsection{CONCLUSION}

This study demonstrates the optimization version of a sleep monitoring system that relates in between surrounding ambient parameters and body vital condition for sleep quality study. Although the presented result is still premature and requires a deep investigation on four elements of ambient that can contribute to the sleep overall sleep quality, the presented result is decisive enough to conclude that the surrounding ambient is impacting the quality of sleep. From the sleep stage and the duration of time in each of the sleep stages, sleep quality and the better surrounding environment for sleeping can be determined. Based on the result of the four sets of experiments, the suitable room ambient to get a better night quality sleep with the temperature slightly lower than normal room temperature, minimalise the use of a humidifier, low intensity of light with all the lamp switch off and lastly with good airflow to the room indicating good air ventilation.

\subsection{ACKNOWLEDGMENTS}

Authors would like to thank the Machine Learning \& Signal Processing (MLSP) research group under Fakulti Kejuruteraan Elektronik dan Kejuruteraan Komputer (FKEKK), of Universiti Teknikal Malaysia Melaka (UTeM) for sponsoring this work under project PJP/2020/FKEKK/PP/S01788 and providing the use of the existing facilities to complete this project.

\subsection{REFERENCES}

[1] V. V. Vyazovskiy, "Sleep, recovery, and metaregulation: explaining the benefits of sleep," Nature and science of sleep, vol. 7, p. 171, 2015.

[2] J. W. Kantelhardt, T. Penzel, S. Rostig, H. F. Becker, S. Havlin, and A. Bunde, "Breathing during REM and non-REM sleep: correlated versus uncorrelated behaviour," Physica A: Statistical Mechanics and its Applications, vol. 319, pp. 447-457, 2003.

[3] J. W. Burns, F. B. Consens, R. J. Little, K. J. Angell, S. Gilman, and 
R. D. Chervin, "EMG variance during polysomnography as an assessment for REM sleep behavior disorder," Sleep, vol. 30, no. 12, pp. 1771-1778, 2007.

[4] R. Ferri et al., "A quantitative statistical analysis of the submentalis muscle EMG amplitude during sleep in normal controls and patients with REM sleep behavior disorder," Journal of sleep research, vol. 17, no. 1, pp. 89-100, 2008.

[5] M. Baboli, A. Singh, B. Soll, O. Boric-Lubecke, and V. M. Lubecke, "Good night: Sleep monitoring using a physiological radar monitoring system integrated with a polysomnography system," IEEE Microwave Magazine, vol. 16, no. 6, pp. 34-41, 2015.

[6] A. Mamelak and J. A. Hobson, "Nightcap: a home-based sleep monitoring system," Sleep, vol. 12, no. 2, pp. 157-166, 1989.

[7] W. H. M. Saad, C. W. Khoo, S. I. A. Rahman, M. M. Ibrahim, and N. H. M. Saad, "Development of sleep monitoring system for observing the effect of the room ambient toward the quality of sleep," IOP Conf. Ser.: Mater. Sci. Eng., vol. 210, p. 012050, Jun. 2017, doi: 10.1088/1757-899X/210/1/012050.

[8] F. Lin et al., "SleepSense: A noncontact and cost-effective sleep monitoring system," IEEE transactions on biomedical circuits and systems, vol. 11, no. 1, pp. 189-202, 2016.

[9] W. H. bin Mohd Saad et al., "Study on the Effect of the Ambient Temperature toward the Quality of Sleep," IJECE, vol. 7, no. 6, p. 2986, Dec. 2017, doi: 10.11591/ijece.v7i6.pp2986-2992.

[10] K. P. Wright Jr, C. Gronfier, J. F. Duffy, and C. A. Czeisler, "Intrinsic period and light intensity determine the phase relationship between melatonin and sleep in humans," Journal of biological rhythms, vol. 20, no. 2, pp. 168-177, 2005.

[11] P. Batog and M. Badura, "Dynamic of Changes in Carbon Dioxide Concentration in Bedrooms," Procedia Engineering, vol. 57, pp. 175-182, Jan. 2013, doi: 10.1016/j.proeng.2013.04.025.

[12] X. Xu et al., "Experimental study on sleep quality affected by carbon dioxide concentration," Indoor air, vol. 31, no. 2, pp. 440453, 2021.

[13] X. Zhang, G. Luo, J. Xie, and J. Liu, "Associations of bedroom air temperature and $\mathrm{CO} 2$ concentration with subjective perceptions and sleep quality during transition seasons," Indoor air, 2021. 
[14] J. Xiong, L. Lan, Z. Lian, and R. De Dear, "Associations of bedroom temperature and ventilation with sleep quality," Science and Technology for the Built Environment, vol. 26, no. 9, pp. 12741284, 2020.

[15] S. I. Jang, J. Han, M. Lee, J. Seo, B. J. Kim, and E. Kim, "A study of skin characteristics according to humidity during sleep," Skin Research and Technology, vol. 25, no. 4, pp. 456-460, 2019.

[16] J. E. Lehto et al., "Circadian preferences and sleep in 15-to 20-year old Finnish students," Sleep Science, vol. 9, no. 2, pp. 78-83, 2016.

[17] İ. Önder, Ş. Beşoluk, M. İskender, E. Masal, and E. Demirhan, "Circadian preferences, sleep quality and sleep patterns, personality, academic motivation and academic achievement of university students," Learning and Individual Differences, vol. 32, pp. 184-192, 2014. 